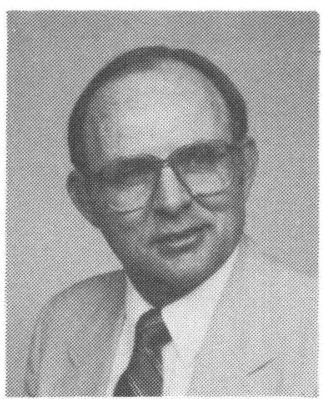

Editorial

Jack D. Gaskill, Editor

\section{On Frequency Doubling and Other Changes}

At the meeting of the SPIE Board of Governors held in Arlington, Virginia, this past spring, a great deal of time was devoted to concerns over the government's involvement in various aspects of the Society's affairs. There were distractions related to technology transfer, distractions due to the establishment of separate export control sessions at the technical symposium, and distractions caused by the presence of the media at the symposium.

Amid all of these distractions, a motion to change the frequency of publication of Optical Engineering from bimonthly to monthly, starting with the January 1986 issue, was suddenly placed before the Board without advance notice. Several of the governors present seemed a bit surprised, but, after a minimum of discussion, the motion passed with only a few dissenting votes. Because the decision to go monthly had been postponed by the Board several times previously, I can only conclude that it must have been the fluctuations in the index of distraction at that meeting that led to a frequency doubling of the Journal. Whatever the reasons, Optical Engineering is definitely going monthly in January!

In addition to the change in publication frequency, the Journal will have a new look between the covers. The type size is being enlarged to make it easier to read, and the boxes that have outlined the figures for many years are being eliminated. Also, if an author is a member or Fellow of SPIE at the time the manuscript is accepted for publication, a notation so indicating will be placed beside that author's name on the title page. Additionally, the format of the references is being expanded to include titles of journal and proceedings papers and book chapters in order to make reference citations more complete and useful.

The SPIE Reports section is being modified and will no longer include Forum columns. We felt that, although interesting and informative, these columns tended to be of a nonarchival nature and probably were better suited to another publication, e.g., Optical Engineering Reports. However, the book reviews and meeting and short course calendars will be retained.

One final change that will be implemented early in 1986 is the following: at the end of each paper will appear brief biographical sketches and photographs of the authors. We believe that this will add a nice touch that will be appreciated by authors and readers alike.

\section{Announcement}

\section{Future Special Issue: Optical Interconnections}

Part of the October 1986 issue of Optical Engineering will be devoted to the topic of optical interconnections. Prospective authors who are doing new work in this field and who may be interested in contributing to this issue are encouraged to contact the Guest Editor, Lynn D. Hutcheson (see address and phone at right).

\section{OPTICAL ENGINEERING EDITORIAL SCHEDULE}

\section{January 1986}

Optical Computing

Raymond Arrathoon

Wayne State University

Dept. of Electrical \& Computer Eng.

$701 \mathrm{~W}$. Warren

Detroit, MI

313/577-3738

February 1986

Materials and Devices for Optical Information Processing

Cardinal Warde M.I.T.

Room 13-3134

Cambridge, MA 02139 617/253-6858

Uzi Efron Hughes Research Labs. M.S. RL69 3011 Malibu Canyon Rd. Malibu, CA 90265 213/317-5214

March 1986

Applications of Artificial Intelligence
$\begin{array}{ll}\text { Mohan M. Trivedi } & \text { John F. Gilmore } \\ \text { Louisiana State Univ. } & \text { Georgia Tech Research } \\ \text { Dept. of Electrical and } & \text { Institute } \\ \text { Computer Engineering } & \text { Artificial Intelligence Branch } \\ \text { Baton Rouge, } & \text { Atlanta, GA 30332 } \\ \text { LA 70803-5901 } & 404 / 894-3471 \\ \text { 504/388-5241 } & \end{array}$

504/388-5241

April 1986

Optics for the Space Station

Henry Lum

Information Sciences, Code SI

Mail Stop 244-7

NASA Ames Research Center

Moffett Field, CA 94035

415/694-6544

\section{June 1986}

\section{Speckle I}

Henri H. Arsenault

Université Laval

Lab. de recherches en optique et laser

Département de physique

Ste-Foy, Quebec

G1K 7 P4 Canada

418/656-2650

July 1986

Speckle II

Henri H. Arsenault

\section{October 1986}

\section{Optical Interconnections}

Lynn D. Hutcheson

Joseph W. Goodman Stanford University Dept. of Electrical Engineering Durand Bldg. 127 Stanford, CA 94305 415/497-3304

\begin{tabular}{l|l} 
Lynn D. Hutcheson \\
Honeywell Inc. \\
10701 Lyndale Ave. South \\
Bloomington, MN 55420 \\
$612 / 887-4052$
\end{tabular}

\begin{tabular}{l|l} 
Lynn D. Hutcheson \\
Honeywell Inc. \\
10701 Lyndale Ave. South \\
Bloomington, MN 55420 \\
$612 / 887-4052$
\end{tabular}

\begin{tabular}{l|l} 
Lynn D. Hutcheson \\
Honeywell Inc. \\
10701 Lyndale Ave. South \\
Bloomington, MN 55420 \\
$612 / 887-4052$
\end{tabular}

\begin{tabular}{l|l} 
Lynn D. Hutcheson \\
Honeywell Inc. \\
10701 Lyndale Ave. South \\
Bloomington, MN 55420 \\
$612 / 887-4052$
\end{tabular} 